\title{
COUPLED MEASUREMENTS OF WATER CONTENT AND ELECTRICAL CONDUCTIVITY IN DIELECTRICALLY LOSSY CLAY SLURRY USING A COATED TDR PROBE
}

\author{
Hideki Miyamoto ${ }^{\text {i) }}$, Jiro Chikushi ${ }^{\text {ii) }}$ and Motohei Kanayama ${ }^{\text {iii) }}$
}

\begin{abstract}
Although time domain reflectometry (TDR) has been widely accepted as a non-destructive in-situ method with high reliability, the effective use of TDR for water content $(w)$ and electrical conductivity (EC) measurements in clay slurry has not been established. We developed a Teflon-coated (TC) probe with a $0.05-\mathrm{mm}$ thick fluorocarbon resin coating, and conducted a calibration experiment for kaolinite slurry to indicate its applicability to the measurements. The TC probe could estimate $w$ from the observed effective dielectric constant $\left(\varepsilon_{\text {eff }}\right)$ in the range of $w \geq 47 \%$ with a $\pm 6 \%$ error range. The $\varepsilon_{\text {eff }}$ includes dielectric constant of two components: material under test $\left(\varepsilon_{\mathrm{m}}\right)$ and coating material $\left(\varepsilon_{\mathrm{tef}}\right)$. The relationship between $\varepsilon_{\text {eff }}$ and $w$ for this particular probe design cannot be directly applied to other coated probes because each probe has its own specific dielectric characteristic. We defined a function expressing the characteristic, that is $\varepsilon_{\text {eff }}$ vs. $\varepsilon_{\mathrm{m}}$, according to the testing in various fluid media. By applying the function, the observed data sets of $\varepsilon_{\mathrm{eff}}$ were transformed for a soil specific value $\left(\varepsilon_{\mathrm{m}}\right)$. Owing to the sufficient agreement of the $\varepsilon_{\mathrm{m}}$ values with those for the uncoated probe, we obtained the data sets of $\varepsilon_{\mathrm{m}}$ vs. $w$ and its empirical expression for kaolinite slurry.
\end{abstract}

Key words: clay mineral, (electrical conductivity), slurry, (time domain reflectometry), water content (IGC: D3)

\section{INTRODUCTION}

The monitoring of water content $(w)$ in high-moistened clay slurry is often conducted to estimate its mechanical properties. The value of $w$ has preferably been determined by an oven-drying method in which the weight of a soil core sample is measured before and after the ovendrying. The method is accurate, but is not helpful for long-term and routine measurements because it is timeconsuming and destructive. Tensiometry to measure water pressure may also be applicable, but it cannot detect the changes of $w$ in the range exceeding a saturated condition. Therefore, the establishment of a nondestructive method to monitor $w$ in high-moistened clay slurry has been desired.

Recently, time domain reflectometry (TDR) using an electromagnetic (EM) signal has become widely accepted as a superior method of measuring volumetric water content $(\theta)$ in soils. Noborio (2001) and Robinson et al. (2003) reviewed the theoretical and technical backgrounds of TDR. In TDR, $\theta$ can be determined from the dielectric constant obtained by analyzing the travel time of a step-pulse signal transmitted from a pulse generator of a TDR cable tester to a probe embedded in soil. The empirical equation proposed by Topp et al. (1980) pro- vides an adequate relationship between $\theta$ and dielectric constant for many soils, except for organic soils and clayey soils. Even for the clayey soils, $\theta$ can be evaluated using the soil-specific curve for an unsaturated range (Dasberg and Hopmans, 1992; Dirksen and Dasberg, 1993). Additionally, electrical conductivity (EC) of the bulk soil can simultaneously be derived from TDR waveform (Dalton et al., 1984). Various types of wellestablished TDR instruments are commercialized.

There are some difficulties when applying TDR to dielectrically lossy and dispersive media. In the conductive soils, the energy of an emitted EM signal attenuates during travel along the sensing part of a TDR probe. When the power of a reflected EM signal attenuates to less than $10 \%$ of the initial level, the end reflection on a TDR waveform becomes difficult to find and TDR measurement can be incomplete (Dalton and van Genuchten, 1986). In aqueous systems, most clay minerals impart a certain degree of electrical conductance due to the mobility of accumulated ions on their charged surfaces; the clays become more conductive with increase in water content due to the promotion of the ionic mobility. This in turn generates the signal loss and consequently limits the measurable range of a TDR in high-moistened clay slurry. Additionally, water bound to clay surfaces exhibits

i) Postdoctoral Research Associate, Biotron Institute, Kyushu University, Japan (miyamotoh@agr.kyushu-u.ac.jp).

ii) Professor, ditto.

iii) Assistant Professor, Kyushu University, Japan.

The manuscript for this paper was received for review on June 3, 2008; approved on December 25, 2008.

Written discussions on this paper should be submitted before November 1, 2009 to the Japanese Geotechnical Society, 4-38-2, Sengoku, Bunkyo-ku, Tokyo 112-0011, Japan. Upon request the closing date may be extended one month. 
dielectric dispersion, i.e., the dielectric constant changes as a function of frequency (Fernando et al., 1977; Robinson et al., 2003). For the clays, the application of current TDR instruments has not been established to date.

For commercial TDR instruments users, the most likely improvement to remove the effect of the signal loss with minimal modification would be to coat over the sensing part of a TDR probe with insulating materials (Kelly et al., 1995; Ferré et al., 1996; Nichol et al., 2002). This may be effective at reducing a certain degree of signal loss occurring in dielectrically lossy soils whereas the effects of the dielectric dispersion on the measurements cannot be excluded. However, the coating in turn reduces the sampling area of a TDR probe and provides questionable accuracy due to its small dielectric constant (Ferré et al., 1998; Knight et al., 1997). Although previous studies employed heat-shrinking tubings as a coating material (Kelly et al., 1995; Nichol et al., 2002), their thickness has an impact on the sensitivity of coupled measurements of dielectric constant and electrical conductivity.

The aim of the present study is to reveal the possibility of $w$ and EC measurements for high-moistened clay slurry using a coated probe with an extremely thin coating of fluorocarbon resin mist. To collect fundamental information on probe performance, the impact of the coating was examined by measuring dielectric constants and bulk EC of various fluid media. The functional relationship between dielectric constant and $w$ for kaolinite, one of the well-known natural clay minerals, was calibrated in highly moistened states. The calibrated equation for kaolinite was also standardized according to the results of examination for fluid media.

\section{MATERIALS AND METHODS}

\section{Probe Testing in Fluid Media}

A designed Teflon-coated (TC) probe consists of three parallel stainless steel electrodes $(100 \mathrm{~mm}$ in length and $1.2 \mathrm{~mm}$ in diameter), and the distance between each electrode is $3.5 \mathrm{~mm}$ (Fig. 1). The central electrode was coated with a fluorocarbon resin mist (Fine Chemical Japan Co., LTD.) by spraying the mist on its surface. To provide a staunch coating, we recoated the electrode with the resin and then sintered it on its surface in a muffle kiln at $220^{\circ} \mathrm{C}$ for 3 hours. The thickness of the coating measured with a caliper was approximately $0.05 \mathrm{~mm}$. The central electrode was connected to the copper core line of in a $2.7-\mathrm{m}$

$0.05-\mathrm{mm}$ thick teflon-coating

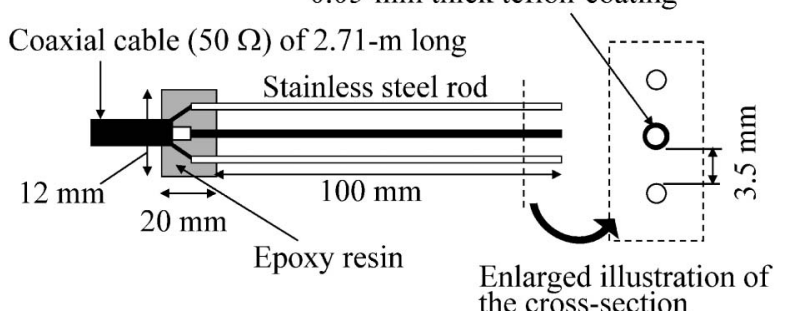

Fig. 1. Schematic diagram of the Teflon-coated probe (TC probe) long coaxial cable of $50 \Omega$, and the two outer electrodes were grounded through the peripheral copper shield part of the coaxial cable. The probe was connected to a Tektronix $1502 \mathrm{C}$ cable tester capable of generating an EM signal in high frequency.

Probe performance can be quantitatively examined by the waveform measurements in fluid media. Distilled water, $\mathrm{CaCl}_{2}$ solutions with different electrical conductivity (EC; $0.14,1.18,10$ and $\left.68 \mathrm{dS} \mathrm{m}^{-1}\right)$, ethanol-water mixtures with different fractions of ethanol $(0.1,0.2,0.3$, $0.4,0.5,0.6,0.7,0.8,0.9$ and $1.0 \mathrm{~kg} \mathrm{~kg}^{-1}$ ) were individually poured into an acrylic plastic cylinder with $50 \mathrm{~mm}$ in internal diameter and $110 \mathrm{~mm}$ in height. TDR waveforms for the fluid media were measured with the cable tester by immersing the probe electrodes. The part of the waveforms including the reflection points at the probe beginning and end were monitored and analyzed with WinTDR (Or et al., 2004). In this study, the point where the waveform for distilled water deviates from that for air was defined to a probe beginning $\left(t_{1}\right)$ (Dirksen, 1999), and was fixed throughout all measurements. The reflection point at a probe end $\left(t_{2}\right)$ was determined by using the algorithm of WinTDR called the flat line method. Travel time $\left(t_{\mathrm{s}}\right)$ of the EM pulse guided along the probe (time from $t_{1}$ to $t_{2}$ ) was determined and then transformed into dielectric constant $\left(\varepsilon_{\mathrm{m}}=\left(\mathrm{c} t_{\mathrm{s}} / 2 \mathrm{~L}\right)^{2}\right.$, where $\mathrm{c}$ is a velocity of light $\left(3.0 \times 10^{8} \mathrm{~m} \mathrm{~s}^{-1}\right)$, and $\mathrm{L}$ is actual length of probe. The return pulse voltage after multiple reflections have died out in the waveform was also determined with WinTDR and bulk EC was then calculated based on an equation shown by Topp et al. (1988), which is incorporated in WinTDR.

For the comparison, EC values and dielectric constants for identical fluid media were measured with a conventional uncoated three-wire probe with the same configuration. Temperature of all the fluid media was kept at $11^{\circ} \mathrm{C}$ during the measurements.

\section{Experiment for Kaolinite Slurry}

The clay used was pure kaolinite, which is reported to show less dielectric dispersion than illite and montmorillonite (Fernand et al., 1977). Physical properties of the kaolinite are $2.65 \mathrm{Mg} \mathrm{m}^{-3}$ of particle density, $72 \%$ of liquid limit, and $28 \%$ of plastic limit (Kanayama et al., 2000). The air-dried kaolinite was initially well-moistened by mixing with distilled water in a plastic bag, and then gradually air-dried keeping a saturated condition until $w$ reached to $47 \%$. The kaolinite was kneaded to form a soil block and then placed on a PVC board (Fig. 2(a)). The clay was entirely sealed with plastic wrap to avoid further evaporation, and kept in a laboratory with an average temperature of $20^{\circ} \mathrm{C}\left( \pm 3^{\circ} \mathrm{C}\right)$.

The TC and the uncoated probes were separately installed into the intermediate height of the soil block. The dielectric constants and bulk ECs of the block were continuously measured every 2 hours until 48 hours elapsed. After the measurements, three subsamples ( $\cong 3 \mathrm{~g}$ ) were extracted from the soil block and were accurately weighed with a balance before and after oven-drying. Averaged $w$ 


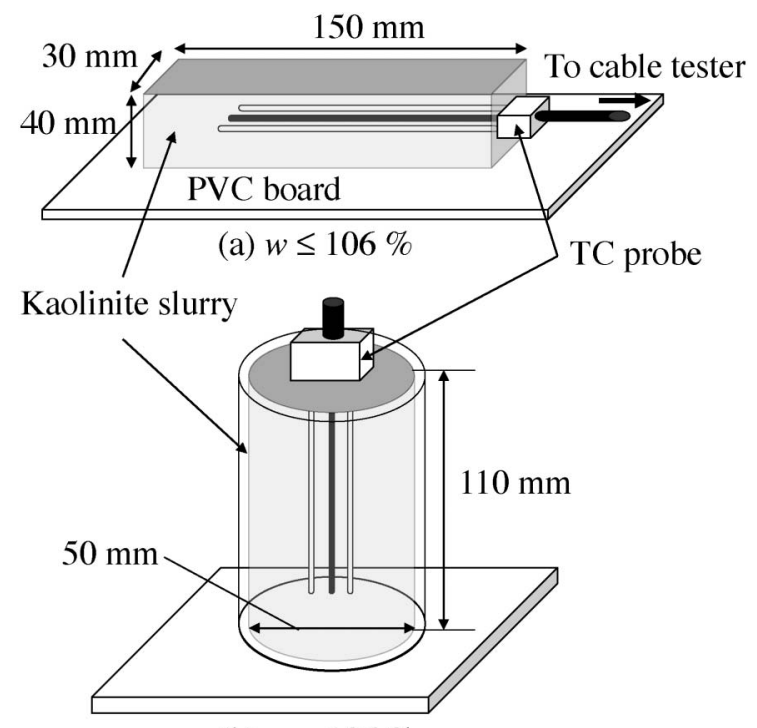

(b) $w>106 \%$

Fig. 2. Schematic diagram of experimental devices for different water content (w) of kaolinite slurries: (a) $w \leq 106 \%$ and (b) $w>106 \%$

for the subsamples was calculated and related to the dielectric constant measured by both probes. The remaining soil block was moistened with distilled water again and tested on the PVC board after the mixing. Repeating the series of procedures by increasing the amount of additional distilled water step-by-step, we investigated the relationship between dielectric constant and $w$ over a wide range. Kaolinite with a higher $w$ is accompanied with high fluidity, and thus the measurements for $w \geq$ $106 \%$ were conducted by inserting the probes vertically into kaolinite slurries stocked in a cylindrical acrylic vessel (Fig. 2(b)). Although the range of our concern is $50 \leq w$ to $200 \%$, the experiment was conducted beyond this range. In the range of $w \geq 213 \%$, it was difficult to keep a uniform condition for 48 hours due to self-consolidation and settlement of clays. Therefore, measurements in such conditions were performed just after the mixing with distilled water.

\section{RESULTS AND DISCUSSION}

\section{Characteristics of the TC Probe}

TDR probes show distinct dielectric characteristics depending on the shape, coating material, and coating thickness. The characteristics were investigated to determine the accuracy of dielectric constant measurement with the TC probe and its measurable range in highly conductive media. To the waveforms obtained for air, distilled water, $\mathrm{CaCl}_{2}$ solutions with different $\mathrm{ECs}$, and ethanol-water mixtures with different ethanol concentrations, the contribution of the coating as well as the fluid media may be included.

The effect of the Teflon-coating on TDR can be verified from TDR waveforms for the $\mathrm{CaCl}_{2}$ solutions (Fig. 3). Since dielectric constant is ascribed to be independent of the EC values in the frequency of TDR, the reflection point at the probe end $\left(t_{2}\right)$ for the solutions should appear

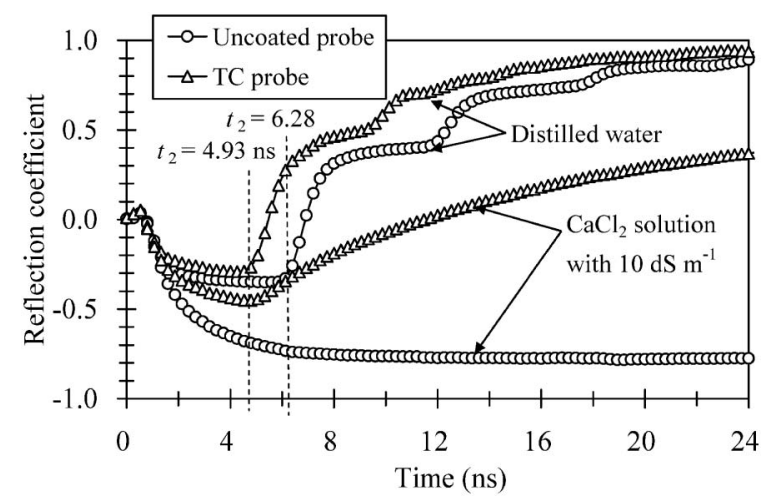

Fig. 3. TDR waveforms for distilled water and $\mathrm{CaCl}_{2}$ solution with $\mathbf{1 0}$ dS $\mathrm{m}^{-1}$ measured with the uncoated probe and the TC probe

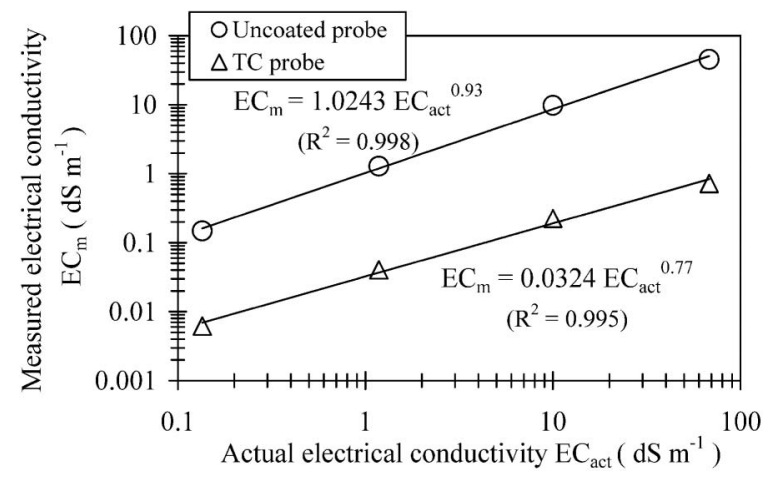

Fig. 4. Measured electrical conductivity $\left(\mathrm{EC}_{\mathrm{m}}\right)$ of $\mathrm{CaCl}_{2}$ solutions for actual electrical conductivity $\left(\mathbf{E C}_{\text {act }}\right)$

at the same position unless the signal has disappeared. For the uncoated probe, the point was identified at the same time, $6.28 \mathrm{~ns}$, for low-conductive fluid media such as distilled water and $\mathrm{CaCl}_{2}$ solutions with $0.14-1.18 \mathrm{dS}$ $\mathrm{m}^{-1}$, but not for $10 \mathrm{dS} \mathrm{m}^{-1}$ or more conductive solutions due to the significant loss of signal (Fig. 3). On the other hand, waveforms for the TC probe indicated a sharp tangent at the same time, $4.93 \mathrm{~ns}$, for the tested $\mathrm{CaCl}_{2}$ solution. Despite the difference in travel time for the probes, the coating was confirmed to be effective to reduce the degree of signal loss; this means the measurable range of TDR can be extended.

The coating also affected the sensitivity of EC and dielectric constant measurements. For the uncoated probe, measured $\mathrm{EC}$ values $\left(\mathrm{EC}_{\mathrm{m}}\right)$ for the $\mathrm{CaCl}_{2}$ solutions generally agreed with actual $\mathrm{EC}$ values $\left(\mathrm{EC}_{\mathrm{act}}\right)$ determined with an EC meter (Fig. 4). The expansion of measurable range is favorable as in Fig. 3, but the values of $\mathrm{EC}_{\mathrm{m}}$ for the TC probe fall below $\mathrm{EC}_{\mathrm{m}}$-values for the uncoated probe in tested $\mathrm{CaCl}_{2}$ solutions (Fig. 4). However, $\mathrm{EC}_{\text {act }}$ can be determined based on the empirical relationship described in Fig. 4 even in using the TC probe.

The dielectric constant $\left(\varepsilon_{\mathrm{m}}\right)$ of ethanol-water mixtures measured with the uncoated probe decreased with ethanol concentration (Fig. 5). Relatively good agreement of the measured $\varepsilon_{\mathrm{m}}$-values with those of More et al. (2006) may ensure the measurements conducted here. On 


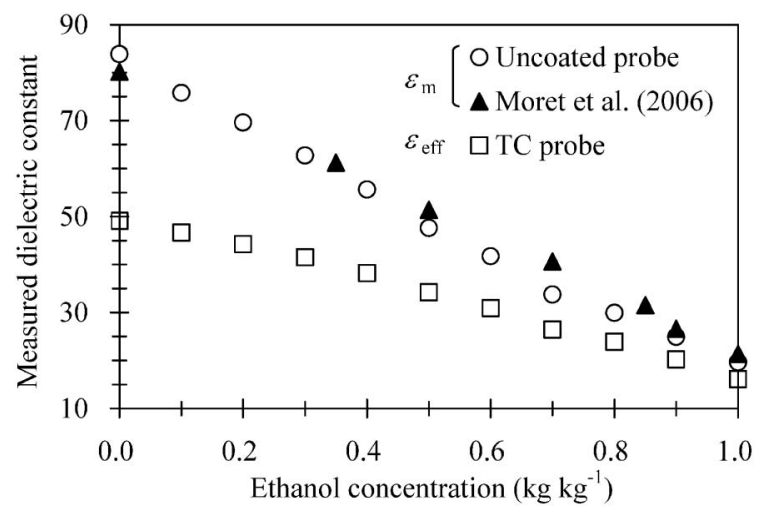

Fig. 5. Dielectric constant measured by the uncoated probe and the TC probe for ethanol concentrations $\left(C_{\text {ethanol }}\right)$ at $11^{\circ} \mathrm{C}$

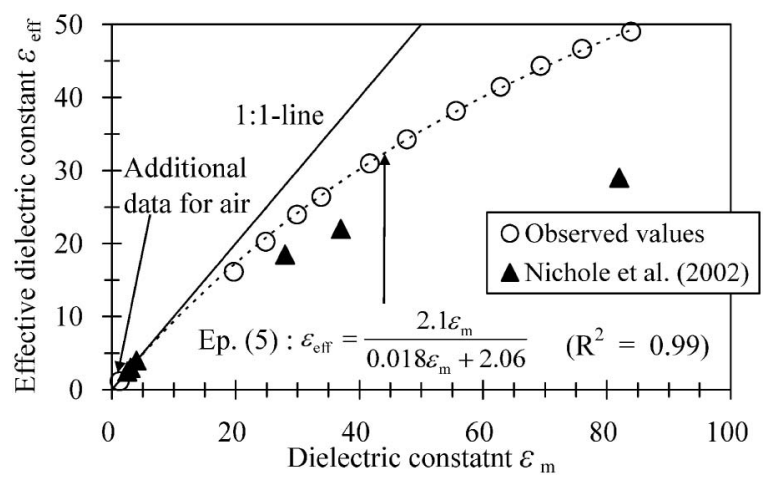

Fig. 6. Effective dielectric constant $\left(\varepsilon_{\text {eff }}\right)$ measured by the TC probe for dielectric constant determined with the uncoated probe $\left(\varepsilon_{\mathrm{m}}\right)$

the other hand, the TC probe determines an effective dielectric constant $\left(\varepsilon_{\text {eff }}\right)$ of the two components; media $\left(\varepsilon_{\mathrm{m}}\right)$ and the fluorocarbon resin coating $\left(\varepsilon_{\mathrm{tef}}\right)$, whereas the uncoated probe can directly determine $\varepsilon_{\mathrm{m}}$. Therefore, the dielectric constants for the TC probe were generally smaller than those for the uncoated probe.

To estimate $\varepsilon_{\mathrm{m}}$ with the TC probe, the obtained $\varepsilon_{\text {eff }}$ must be directly related to $\varepsilon_{\mathrm{m}}$ for the uncoated probe (Fig. $6)$. Due to the disparity between the 1:1-line and $\varepsilon_{\text {eff }}$ values in Fig. 6, the TC probe can be recognized as less sensitive to the change in dielectric constant than the uncoated probe in media having higher $\varepsilon_{\mathrm{m}}$-values. Although Nichol et al. (2002) who adopted a 0.4-mm thick coated probe (Fig. 6) also reported similar results. The present TC probe with the thinner coating of $0.05-\mathrm{mm}$ thick was more sensitive than their coated probe.

We will consider the $\varepsilon_{\text {eff }}$ of a multiphase mixture measured with a TDR probe. The $\varepsilon_{\text {eff }}$ depends on dielectric constant of all constituents, their volumetric ratios, and their interaction. According to dielectric mixing model (Birchak et al., 1974), the $\varepsilon_{\text {eff }}$ measured with the TC probe can be expressed as the following two-phase mixing formula:

$$
\varepsilon_{\text {eff }}=\left\{n \varepsilon_{\mathrm{m}}^{\alpha}+(1-n) \varepsilon_{\text {tef }}^{\alpha}\right\}^{1 / \alpha}
$$

where $n$ is the volumetric fraction of a measuring medium, $\varepsilon_{\text {tef }}$ is dielectric constant of Teflon-coating $(=2.1$, Or et al., 2004), and $\alpha$ is a geometrical exponent of them with respect to the direction of the electric field around the probe. In the measurement with the $\mathrm{TC}$ probe, the direction of the electric field is perpendicular to their layer; the value of $\alpha$ is -1 (Roth et al., 1990). Thus, Eq. (1) can be simplified as:

$$
\varepsilon_{\text {eff }}=\frac{\varepsilon_{\mathrm{m}} \varepsilon_{\mathrm{tef}}}{(1-n) \varepsilon_{\mathrm{m}}+n \varepsilon_{\mathrm{tef}}}
$$

By fitting Eq. (2) to the data sets observed (Fig. 6), we optimized $n$ as 0.982 . Thus, the following empirical relationship between $\varepsilon_{\mathrm{m}}$ and $\varepsilon_{\text {eff }}$ was obtained by substituting the values of $n$ and $\varepsilon_{\text {tef }}(=2.1)$ into Eq. (2) as:

$$
\varepsilon_{\text {eff }}=\frac{2.1 \varepsilon_{\mathrm{m}}}{(1-0.982) \varepsilon_{\mathrm{m}}+0.982 \times 2.1}=\frac{2.1 \varepsilon_{\mathrm{m}}}{0.018 \varepsilon_{\mathrm{m}}+2.06}
$$

It is possible to inversely evaluate $\varepsilon_{\mathrm{m}}$ from $\varepsilon_{\mathrm{eff}}$ observed by applying Eq. (3). This type of transformation may be convenient to standardize $\varepsilon_{\text {eff }}$-values obtained directly with the TC probe.

\section{Bulk EC and Water Content Measurement}

The bulk EC values of kaolinite slurry $\left(E_{k}\right)$, calculated by the empirical equation in Fig. 4, changed with $w$ (Fig. 7). The $\mathrm{EC}_{\mathrm{k}}$ was initially 3.9-5.2 $\mathrm{dS} \mathrm{m}^{-1}$ at $w=47 \%$ and decreased with $w$. The high conductivity at a lower $w$ would be due to the presence of accumulated soluble ions on the clay surface. The slurry at $w \leq 102 \%$ was still too conductive to use the uncoated probe, i.e., we could not identify the reflection point at the probe end $\left(t_{2}\right)$ because the slope of waveforms around the point was too small due to the transmission losses of signal (Fig. 8(a)). However, the slope gradually increased with $w$ and the waveforms at the probe end became sharper. Therefore, we could successfully determine the travel time in $w>$ $102 \%$.

Compared with the uncoated probe, the reflection points at the probe end for the TC probe generally shifted to the shorter time (Fig. 8(b)). The point for each condition moved to longer time with $w$ as well as with the uncoated probe. The identification of the point was possible even at low $w$ conditions of 47 and $104 \%$ for the TC probe. This indicates that the probe coating can extend the measurable range of TDR to a lower range of $w$.

The $w$ was stably and efficiently measured by using the TC probe (Figs. 9 and 10). The higher the $w$ of slurry is, the larger the $\varepsilon_{\text {eff }}$ becomes. The $\varepsilon_{\text {eff }}$ for $w=143 \%$ was more stable with time than that for $w=47 \%$, because analytical error reduced with $w$ due to the changes of the waveform at the probe end. To reduce the errors, the averaged $\varepsilon_{\text {eff }}$ value of last 10 -data plots was used to relate with $w$ (Fig. 10). The $\varepsilon_{\text {eff }}$ increases with $w$ linearly, and the relationship between $\varepsilon_{\text {eff }}$ and $w$ can be expressed as follows:

$$
w=15.1 \varepsilon_{\mathrm{eff}}-448 \quad(47 \leq w \leq 178 \%)
$$

This empirical equation generally agreed with the measured data sets with $\pm 6 \%$ error range (drawn by a couple of broken lines in Fig. 10). For the experimented range of 


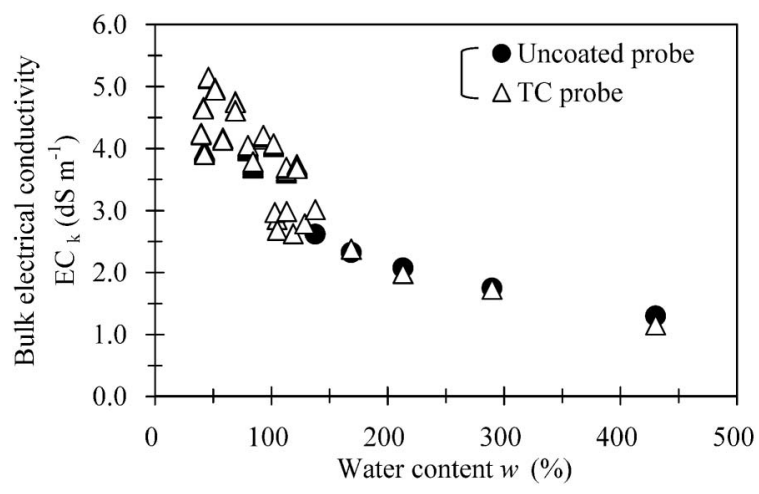

Fig. 7. Bulk electrical conductivity $\left(\mathbf{E C}_{\mathbf{k}}\right)$ of kaolinite slurry for water content $(w)$
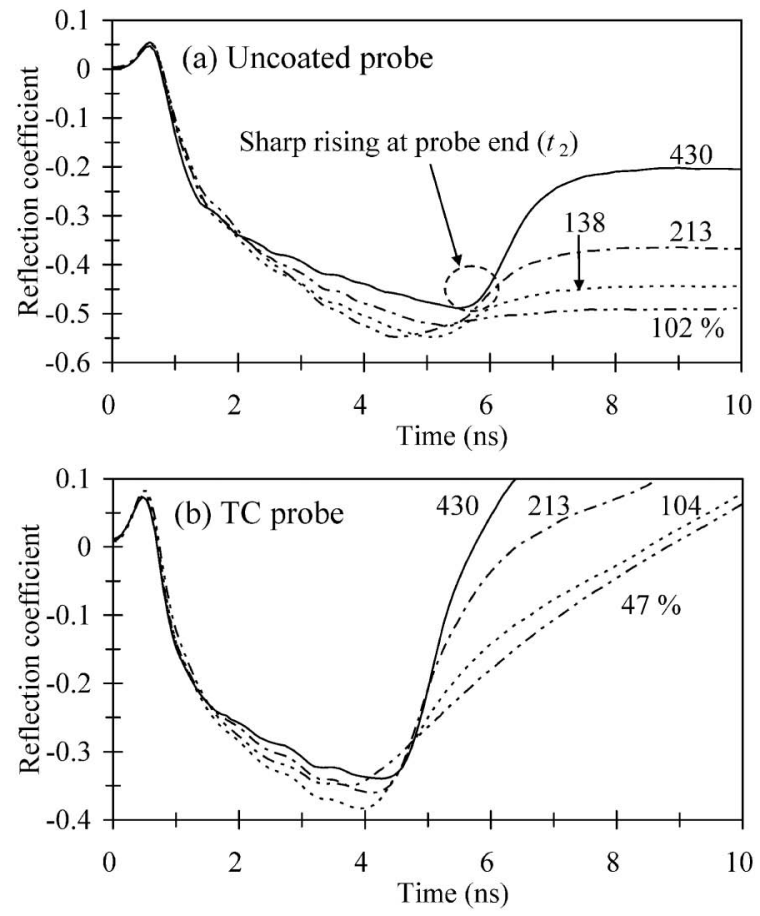

Fig. 8. TDR waveforms measured by (a) the uncoated probe and (b) the TC probe for the kaolinite with different water content (w)

$w \geq 47 \%$, we can satisfactorily evaluate $w$ of kaolinite slurry by using the TC probe. This result tends to indicate that we can conduct $w$ measurement for other lossy clay by using the present $\mathrm{TC}$ probe if the clay is less dispersive than kaolinite.

\section{Standardization of Data Obtained}

The $w$ of kaolinite slurry can be evaluated from $\varepsilon_{\text {eff }}$ using the calibrated equation (Eq. (4)). However, the value of $\varepsilon_{\text {eff }}$ for a specific $w$ depends on the configurations of coated probes. To exclude the impact of Teflon-coating from the measurement, the data set of $\varepsilon_{\text {eff }}$ was standardized by substituting it into rewritten Eq. (2) as,

$$
\varepsilon_{\mathrm{m}}=\frac{2.06 \varepsilon_{\mathrm{eff}}}{2.1-0.018 \varepsilon_{\mathrm{eff}}}
$$

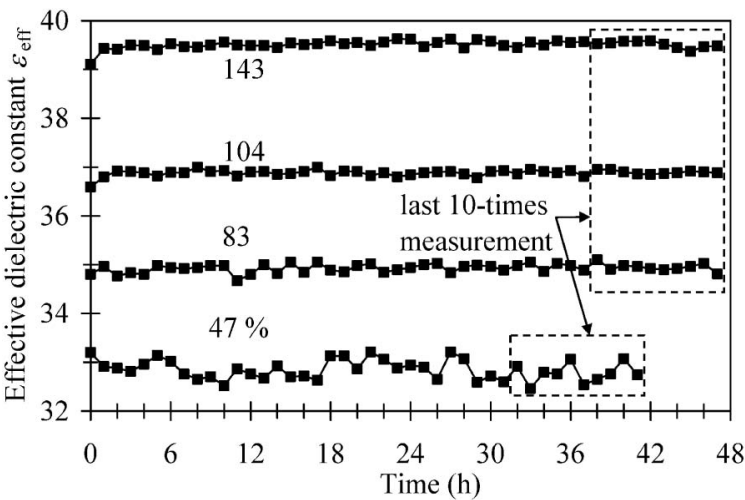

Fig. 9. Changes in effective dielectric constant $\left(\varepsilon_{\text {eff }}\right)$ measured by the TC probe for the kaolinite with different water content $(w=47,83$, 104 and $143 \%$ )

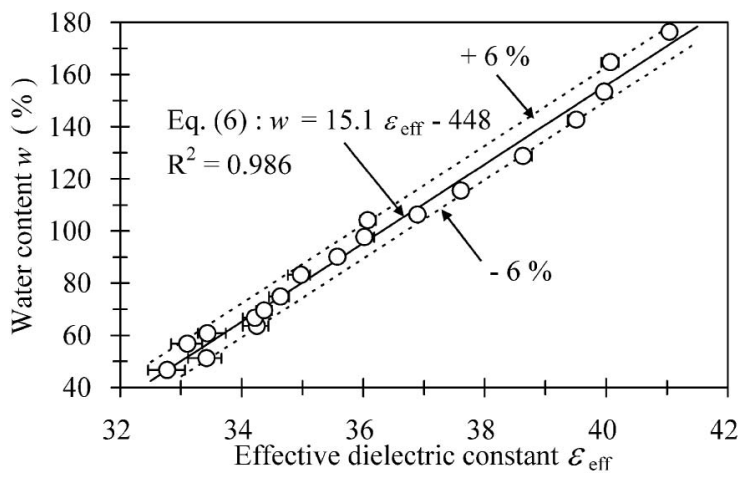

Fig. 10. Water content ( $w$ ) of the kaolinite for effective dielectric constant $\left(\varepsilon_{\text {eff }}\right)$

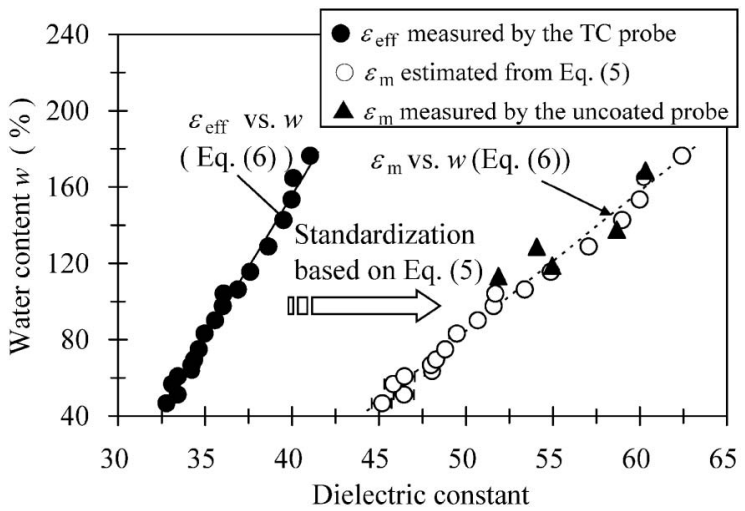

Fig. 11. Water content (w) of the kaolinite for dielectric constant

and we obtained values of $\varepsilon_{\mathrm{m}}$ for different $w$ (Fig. 11). The $\varepsilon_{\mathrm{m}}$-values estimated through Eq. (5) were generally compatible to those directly obtained by the uncoated probe, although the measurable range of the uncoated probe was limited to higher $w$ (Fig. 11) corresponding to lower conductivity (Fig. 7). This agreement indicates that the standardized data sets satisfied the actual $\varepsilon_{\mathrm{m}}$ for the uncoated probe.

Using all the data sets obtained with both probes, we finally obtained an alternative expression within the range 
of our concern:

$$
w=7.3 \varepsilon_{\mathrm{m}}-228 \quad(47 \leq w \leq 178 \%)
$$

Equation (6) is valid to evaluate $w$ of the kaolinite using the presented TC probe. Similarly, Eq. (6) can be applicable to other coated probes if $\varepsilon_{\mathrm{m}}$ in the expression is transformed into $\varepsilon_{\text {eff }}$ by Eq. (2) with a known $n$-value. The use of Eq. (2) to determine $n$-value with fluid media would be more practical than conducting calibration experiments for clay slurry.

\section{CONCLUSION}

To establish the application of time domain reflectometry (TDR) to coupled measurements of water content $(w)$ and bulk electrical conductivity (EC) in dielectrically lossy clay slurry, a Teflon-coated (TC) probe with a thinner coating was developed and tested for kaolinite with different water contents. The TC probe showed a wider measurable range in high-conductive fluid media and higher sensitivity to the change in dielectric constant $\left(\varepsilon_{\mathrm{m}}\right)$ than other coated probes in the previous studies. The probe had enough sensitivity to estimate $w$ from effective dielectric constant $\left(\varepsilon_{\text {eff }}\right)$ within a $\pm 6 \%$ error range, and a wide effective range for $w$ even in high-conductive kaolinite slurry (Fig. 10).

Though extending the measurable range, the use of a coated TDR probe caused another problem in that the observed relation of $w$ and $\varepsilon_{\text {eff }}$ and its calibrated equation (Eq. (4)) are valid only for the TC probe because the $\varepsilon_{\text {eff }}$ includes the component of a coating. To standardize the $\varepsilon_{\text {eff }}$, the $\varepsilon_{\text {eff }}$ was converted into $\varepsilon_{\mathrm{m}}$ by the calibrated equation of $\varepsilon_{\mathrm{m}}$ vs. $\varepsilon_{\text {eff }}$ (Eqs. (3) and (5)) for fluid media. This suggests that a probe-specific equation such as Eq. (4) would be easily obtained inversely if a probe-specific parameter $(n)$ in Eq. (2) has been quantitatively defined for fluid media.

In this study, we demonstrated that the use of the TC probe makes it possible to measure pervasive $w$ and bulk EC even in conductive soils. Although the method shown here may not be effective in strongly dispersive clays, an important point is that clays do not always indicate strong dielectric dispersion; the kaolinite is less dispersive than illite and montmorillonite (Fernando et al., 1977). Despite the lack of information for a lower range of $w$ and other clays, for in situ monitoring we believe that the method shown here would be more practical than the traditional oven-drying method because it has many advantages: a function measuring both $w$ and bulk EC with minimal soil disturbance, simple multiplexing and automation of their measurement, and the high availability of commercial TDR instruments. However, it was found that the measurement accuracy of the present method was inferior to one of the oven-drying method. Therefore, further investigation on the way to improve the measurement accuracy of TDR with the TC probe should be performed hereafter.

\section{REFERENCES}

1) Birchak, J. R., Gardner, C. G., Hipp, J. E. and Victor, J. M. (1974): High dielectric constant microwave probes for sensing soil moisture, Proc. IEEE, 62(1), 93-98.

2) Dalton, F. N., Herkelrath, W. N., Rawlins, D. S. and Rhoades, J. D. (1984): Time-domain reflectometry: simultaneous measurement of soil water content and electrical conductivity with a single probe, Science, 224, 898-990.

3) Dalton, F. N. and van Genuchten, M. Th. (1986): The time-domain reflectometry method for measuring soil water content and salinity, Geoderma, 38, 237-250.

4) Dasberg, S. and Hopmans, J. W. (1992): Time domain reflectometry calibration for uniformly and non-uniformly wetted sandy and clayey loam soils, Soil Sci. Soc. Am. J., 56, 1341-1345.

5) Dirksen, C. and Dasberg, S. (1993): Improved calibration of time domain reflectometry soil water content measurements, Soil Sci. Soc. Am. J., 57, 660-667.

6) Dirksen, C. (1999): Soil Physics Measurements, CATENA VERLAG GMBH, Germany.

7) Fernando, M. J., Burau, R. G. and Arulanandan, K. (1977): A new approach to determination of cation exchange capacity, Soil Sci. Soc. Am. J., 41, 818-820.

8) Ferré, P. A., Rudolph, D. L. and Kachanoski, R. G. (1996): Spatial averaging of water content by time domain reflectometry: Implications for twin rod probes with and without dielectric coating, Water Resour. Res., 32, 271-279.

9) Ferré, P. A., Knight, J. H., Rudolph, D. L. and Kachanoski, R. G. (1998): The sample area of conventional and alternative time domain reflectometry probe, Water Resour. Res., 34(11), 2971-2979.

10) Kanayama, M., Ohtsubo, M., Higashi, T., Hiyama, H. and Takayama, M. (2000): Effect of pore water salinity on the consolidation characteristics of clay, Proc. International Symposium on Lowland Technology, International Association of Lowland Technology, 113-120.

11) Kelly, S. F., Selker, J. S. and Green, J. L. (1995): Using short soil moisture probes with high-bandwidth time domain reflectometry instruments, Soil Sci. Soc. Am. J., 59, 97-102.

12) Knight, J. H., Ferré, P. A., Rudolph, D. L. and Kachanoski, R. G. (1997): A numerical analysis of the effects of coatings and gaps upon relative dielectric permittivity measurement with time domain reflectometry, Water Resour. Res., 33, 1455-1460.

13) Moret, D., Arrúe, J. L., López, M. V. and Gracia, R. (2006): A new TDR waveform analysis approach for soil moisture profiling using a single probe, J. Hydrology, 321, 163-172.

14) Nichol, C., Beckie, R. and Smith, L. (2002): Evaluation of uncoated and coated time domain reflectometry probes for high electrical conductivity systems, Soil Sci. Soc. Am. J., 66, 1454-1465.

15) Noborio, K. (2001): Measurement of soil water content and electrical conductivity by time domain reflectometry, Computers and Electronics in Agriculture, 31, 213-237.

16) Or, D., Jones, S. B., VanShaar, J. R., Humphries, S. and Koberstein, L. (2004): Users Guide of WinTDR, Utah States University, http://soilphysics.usu.edu/wintdr/index.htm.

17) Robinson, D. A., Jones, S. B., Wraith, J. M., Or, D. and Friedman, S. P. (2003): A review of advances in dielectric and electrical conductivity measurement in soils using time domain reflectometry, Vadose Zone J., 2, 444-475.

18) Roth, K., Schulin, R., Flühler, H. and Attinger, W. (1990): Calibration of time domain reflectometry for water content measurement using composite dielectric approach, Water Resour. Res., 26, 2267-2273.

19) Topp, G. C., Davis, J. L. and Annan, A. P. (1980): Electromagnetic determination of soil water content: measurements in coaxial transmission lines, Water Resour. Res., 16, 574-582.

20) Topp, G. C., Yanuka, M., Zebchuk, W. D. and Zegelin, S. J. (1988): Determination of electrical conductivity using time domain reflectometry: Soil and water experiments in coaxial line, Water Resour. Res., 24, 945-952. 